J. Asiat. Soc. Bangladesh, Sci. 40(2): 231-241, December 2014

\title{
SPERM AND EGG QUALITY IN CATLA AND RUI BETWEEN SPAWNING SEASONS IN BANGLADESH
}

\author{
MAHMUD HASAN ${ }^{*}$, MD. MOFIZUR RAHMAN ${ }^{2}$, ANWAR HOSSAIN ${ }^{1}$ \\ AND MD. GOLAM RABBANE' \\ 'Department of Fisheries, University of Dhaka, Dhaka-1000, Bangladesh \\ ${ }^{2}$ Department of Fisheries and Marine Science, Noakhali Science and Technology University, \\ Noakhali-3814, Bangladesh
}

\begin{abstract}
Sperm and egg quality of catla Catla catla and rui Labeo rohita were investigated in Brahmaputra and Sarker Hatchery, Mymensingh, Bangladesh over two spawning seasons as early (March to May) and peak (June to August ). In both hatcheries, catla and rui produced nearly $90 \%$ motile sperms as well as higher sperm concentration (catla: Brahmaputra hatchery, $2553.33 \pm 119.65$ million $\mathrm{mL}^{-1}$ and Sarker hatchery, $2658.89 \pm$ 76.55 million $\mathrm{mL}^{-1}$; rui: Brahmaputra hatchery, $2856.67 \pm 67.57$ million $\mathrm{mL}^{-1}$ and Sarker hatchery, $2811.67 \pm 51.90$ million $\mathrm{mL}^{-1}$ ), seminal $\mathrm{pH}$ (catla: Brahmaputra hatchery, 7.41 \pm 0.06 and Sarker hatchery, $7.41 \pm 0.06$; rui: Brahmaputra hatchery, $7.39 \pm 0.05$ and Sarker hatchery, $7.35 \pm 0.05$ ) and fertilizability in catla were $88 \%$ and in rui $92 \%$ in both hatcheries in the peak season. The occurrence of opaque eggs in catla and rui was $12 \%$ and $8 \%$ in both hatcheries in the peak season, respectively. The present study points to the fact that the quality of fish sperm and egg depends on seasons.
\end{abstract}

Key words: Egg quality, Spawning, Hatchery, Catla, Rui, Bangladesh

\section{Introduction}

Sperm and egg quality are two major elements for the production of high quality fish seed. Production of healthy larvae mostly depends on the quality of eggs and sperm. Sperm quality plays an important role in fertilizing the eggs. Good quality sperm also can ensure the production of valuable offspring for aquaculture (Bromage and Roberts 1995). Catla Catla catla and rui Labeo rohita, two Indian major carps, are top two aquaculture producing species in the world (FAO 2012). Indian major carps contribute nearly 23.82 $\%$ of the total farm fish yield in Bangladesh. To supplement this production, nearly $97.82 \%$ of the total hatchlings ( 611.48 tones spawn) are being produced in 947 hatcheries (DoF 2012). However, the production and the supply of fish spawn from these hatcheries are not reliable in terms of quality and quantity in relation to the demand particularly in the early spawning season. Poor fry/fingerling production performance between spawning seasons results in higher production cost, lower quantity of seed and lesser access by the end users.

\footnotetext{
• Corresponding author: Email: mhasan@du.ac.bd
} 
Catla and rui reproduce in late spring and summer (March-August) when water temperature remains relatively high. However, they do not spawn equally between early and peak spawning seasons.

Lower rate of fertilization has been observed in March-May (early season) compared to that of peak season (June-August) (pers. comm.). The lower fertilizability in the early spawning season could have resulted poor quality of sperms and eggs. As a result, in the early season, hatchery owners cannot produce the required quantity of fish seed in the earlier beginning of the culture season (February-March). Early stocking extends the culture duration of warmer season which will help to increase the yield of fish.

Sperm and egg qualities have been well studied in salmonids and in some freshwater fishes (Morisawa et al. 1983b, Billard et al. 1995 and Alavi et al. 2008). Sperm biology of common carp, Cyrinus carpio has been reported by Billard et al. (1995). Bozkurt et al. (2008) have reported the spermatological parameters (sperm volume, motility, density and $\mathrm{pH}$ ) and their relationships with seminal plasma composition in grass carps Ctenopharyngodon idella. Alavi et al. (2008) have also demonstrated a seasonal change in sperm morphology, density, motility and seminal plasma composition in the barbell, Barbus barbus. However, changes in sperm and egg quality between spawning seasons in catla and rui have never been reported. The current study was, therefore, designed to investigate the sperm and egg quality of catla and rui between early and peak spawning seasons in Bangladesh.

\section{Materials and Methods}

Catla $(59.9 \pm 2.2 \mathrm{~cm} ; 3.5 \pm 0.2 \mathrm{~kg}$; mean $\pm \mathrm{SE})$ and rui $(61.9 \pm 0.6 \mathrm{~cm} ; 3.1 \pm 0.3 \mathrm{~kg}$; mean $\pm \mathrm{SE}$ ), a total of 720 brood fishes of Brahmaputra and Sarker Hatchery, Mymensingh, Bangladesh were used as the experimental fishes. This study was undertaken during the regular commercial operation of the above mentioned hatcheries between March and August in 2010. Two spawning seasons were: i) early (March to May) and ii) peak (June to August).

Conditioning and hormonal induction of brood fishes: After collection, the selected male and female brood fishes were conditioned separately by holding them in $1,600 \mathrm{~L}$ flowthrough-tank system for a period of 6 hours prior to induction hormone. For this reason, the hormonal solution was prepared and applied to the brood fishes following standard protocols (Chondar 1994). Human chorionic gonadotropin (HCG; Fuda Hormone Factory, Xiamen, China) and the extract of the commercially available pituitary gland (PG; Ducamar Company, Cantabria, Spain) were used as stimulating agents. Female fishes were given a dose of $200 \mathrm{IU} \mathrm{HCG} \mathrm{kg}^{-1}$ body weight (BW) as stimulating dose at $6.0 \mathrm{pm}$ and $500 \mathrm{IU} \mathrm{HCG}+3 \mathrm{mg} \mathrm{PG} \mathrm{kg}^{-1} \mathrm{BW}$ as a resolving dose was induced after 6.0 hours of $1^{\text {st }}$ dose. On the other hand, $2 \mathrm{mg} \mathrm{PG} \mathrm{kg}^{-1} \mathrm{BW}$ was applied in males fishes. 
Milt and egg collection: Milt samples were collected in sterilized plastic vials from induced sexually matured male $(n=5)$ by pressing gently on the abdomen. Samples were drawn every week during the entire study period with three replicates. Males were used repeatedly across the seasons. Eggs were collected in a plastic bowl $(20 \mathrm{~L})$ by stripping induced females $(n=5)$ immediately after ovulation and mixed with milt for fertilization. After 8 hours of fertilization, the rate of fertilization was determined by examining a minimum of 150 eggs per replicate following the technique described by Butts et al. (2009).

Detection of sperm motility (\%): Sperm motility was determined immediately after collection of fresh milt sample. Freshly collected milt sample was diluted with $0.3 \%$ $\mathrm{NaCl}$ (activating solution) at $10: 1$ ratio $(10 \mathrm{~mL}$ activation solution and $1 \mathrm{~mL}$ milt sample). Diluted samples ( $4-5 \mu \mathrm{L})$ was placed on a slide covered by a cover slip $(22 \times 22$ $\mathrm{mm}$ ) and sperm motility was determined using a microscope (biomicroscope, XSZ21$5 \mathrm{DN}$, China) connected with a laptop (DELL, Germany) at 1600x magnification and expressed as percentage following the method described by Rahman et al. (2011).

Determination of sperm concentration (million $m L^{-1}$ ): Sperm concentration was determined using improved Neubauer counting chamber (NCC) (area $1 \mathrm{~mm}^{2}$ and depth $0.1 \mathrm{~mm}$; Germany). To determine the concentration of sperm, milt sample was diluted with $0.3 \% \mathrm{NaCl}$ solution at 1000:1 ratio and was placed on the NCC with a cover slip to settle down within $10 \mathrm{~min}$ rest. Then the sperm cells were counted by a compound light microscope (LABOMED CXRII, USA) at 160x magnification connected to a CCD camera (Unican, HV-2616, Japan) and picture was displayed on a monitor (Samsung 17 inch CRT monitor, Japan) through a TV card (PERPECT Smart Power, China). Sperm concentration was calculated following Alavi et al. (2006) method.

Seminal pH: Milt samples were centrifuged (REMI RM12C, Laboratory Centrifuge, Germany) for $10 \mathrm{~min}$ at room temperature at $8,000 \mathrm{~g}$ to separate the seminal plasma and seminal $\mathrm{pH}$ was measured using standard $\mathrm{pH}$ electrodes after $30 \mathrm{~min}$ of sampling.

Data Analysis: All percent data were transformed into square root before statistical analysis, while sperm concentration data were transformed into natural log. Data were analyzed using ANOVA followed by Tukey's HSD post hoc for multiple comparisons. Data have been presented as mean \pm SEM and analyzed by using the statistical software SPSS version 10.0 with the level of significance at $\mathrm{p}<0.05$.

\section{Results and Discussion}

Sperm Motility (\%): In the both studied hatcheries, no significant difference was observed in sperm motility between two seasons although peak season had a higher trend in catla (Fig. IA and Plate 1a). In rui, almost $90 \%$ sperm was found motile in both seasons of Brahmaputra and Sarker hatchery without significant differences (Fig. 1B; Plate $1 \mathrm{~b}$ ). This increasing trend of sperm motility during peak spawning season in both fishes and hatcheries denotes species specific characteristics as well as indicates 
comparatively more suitable period for producing motile sperm by catla and rui. The findings are in agreement with Akcay et al. (2004) in mirror carp Cyprinus carpio var. specularis.

Sperm Concentration (millions $\mathrm{mL}^{-1}$ ): In both hatcheries, the peak season had significantly higher sperm concentration in catla as compared to the early season (Fig. 2A). Similar to catla, rui also had the highest sperm density in peak season compared to that in the early (Fig. 2B). The observed higher concentration of sperm in the peak compared to that of early season in catla and rui could have resulted from their readiness and responsiveness in the peak season. In addition, this difference in the density of sperm in both species from both hatcheries between spawning seasons could have resulted from discontinuous spermatogenesis. Moreover, inadequate environmental cues and natural feed assemblage could be responsible for variation in sperm concentration. Alavi et al. (2008) have demonstrated a similar change in sperm concentration across the spawning season (18.81 $\times 10^{9}$ in March to $12.45 \times 10^{9} \mathrm{~mL}^{-1}$ in May) in barbel. Changes in sperm concentration could also be related to differences in hormonal stimulation methods, environmental conditions, age and size of the broods (Piros et al. 2002).

\section{A. Catla, Catla catla}

(a) Brahmaputra Hatchery

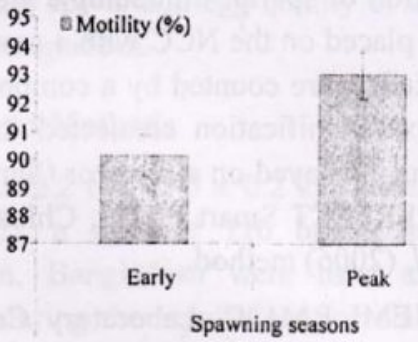

1B. Rui , Labeo rohita

(a) Brahmaputra Hatchery

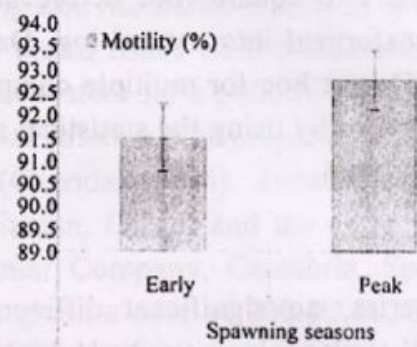

(b) Sarker Hatchery

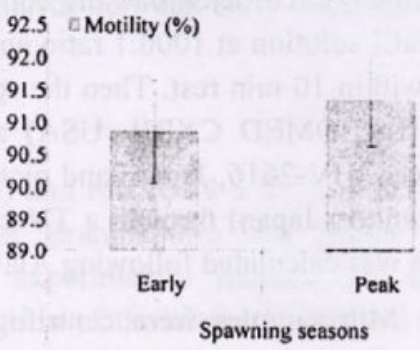

(b) Sarker Hatchery

aotility (\%)

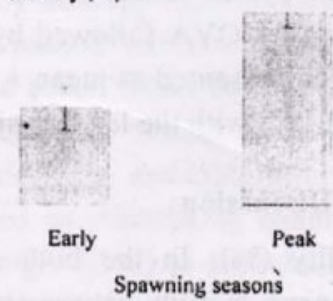

Fig. 1. (A-B) Weekly mean sperm motility rate (\%) in catla Catla catla and rui Labeo rohita found in two spawning seasons during the regular commercial operation in Brahmaputra (a) and Sarker (b) Hatcheries, Mymensingh, Bangladesh. The values (mean $\pm \mathrm{SE}$ ) are significantly different (ANOVA, HSD; $\mathrm{p}<0.05$ ). 
Seminal pH: In both hatcheries, while compared, the highest level of seminal pH of catla was observed in the peak season (Fig. 3A). Similar to catla, in both hatcheries, rui had also higher level of semen $\mathrm{pH}$ in peak season than in early season (Fig. 3B). In both hatcheries, the observed declining trend in seminal $\mathrm{pH}$ from peak to early season in both catla and rui clearly indicates the seasonal effect. The environmental changes and complex chemistry among the seminal plasma components could have caused this falling trend in seminal pH of both hatcheries.

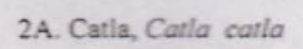

(a) Brahmaputra Hatchery

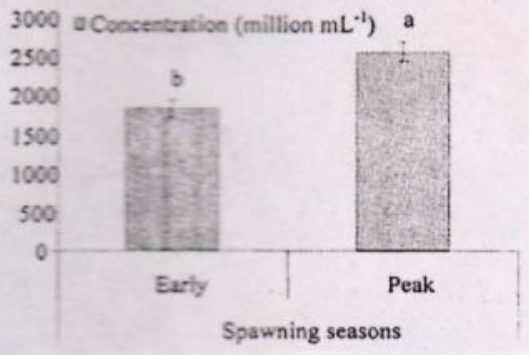

2B. Rui , Labeo rohita

(a) Brahmaputra Hatchery

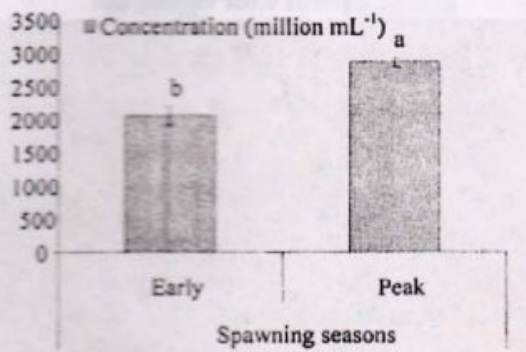

(b) Sarker Hatchery

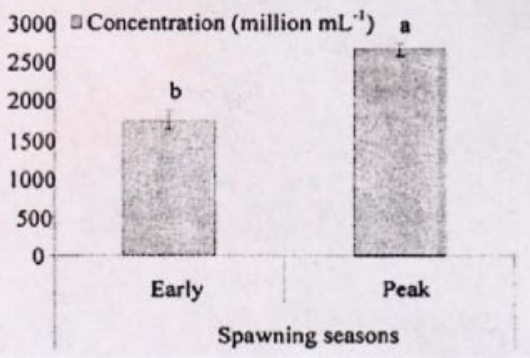

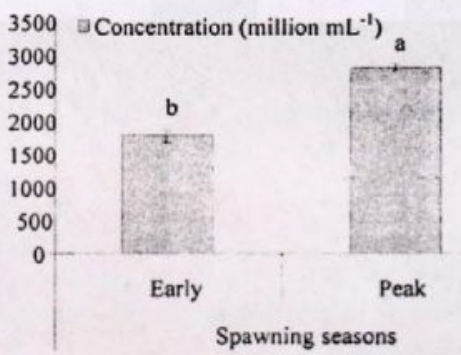

Fig. 2 (A-B). Weekly mean sperm concentration (million $\mathrm{mL}^{-1}$ ) in catla Catla catla and rui Labeo rohita found in two spawning seasons during the regular commercial operation in Brahmaputra (a) and Sarker (b) Hatcheries, Mymensingh, Bangladesh. The values (mean \pm $\mathrm{SE})$ are significantly different (ANOVA, HSD; $\mathrm{p}<0.05$ ).

No single constituent, but the combined effect of all seminal plasma ingredients are responsible for this change in milt $\mathrm{pH}$ throughout the spawning seasons. Similar findings have been confirmed by Emri et al. (1998) in common carp and Bozkurt et al. (2008) in grass carp. The increasing trend of sperm motility in catla and rui in both hatcheries denotes species specific characteristics. The observed higher sperm motility in the peak season indicates that the peaks season would be more suitable for producing motile sperm by catla and rui. The findings of this study are in agreement with the findings of Akcay et al. (2004) in mirror carp Cyprinus carpio var. specularis. 


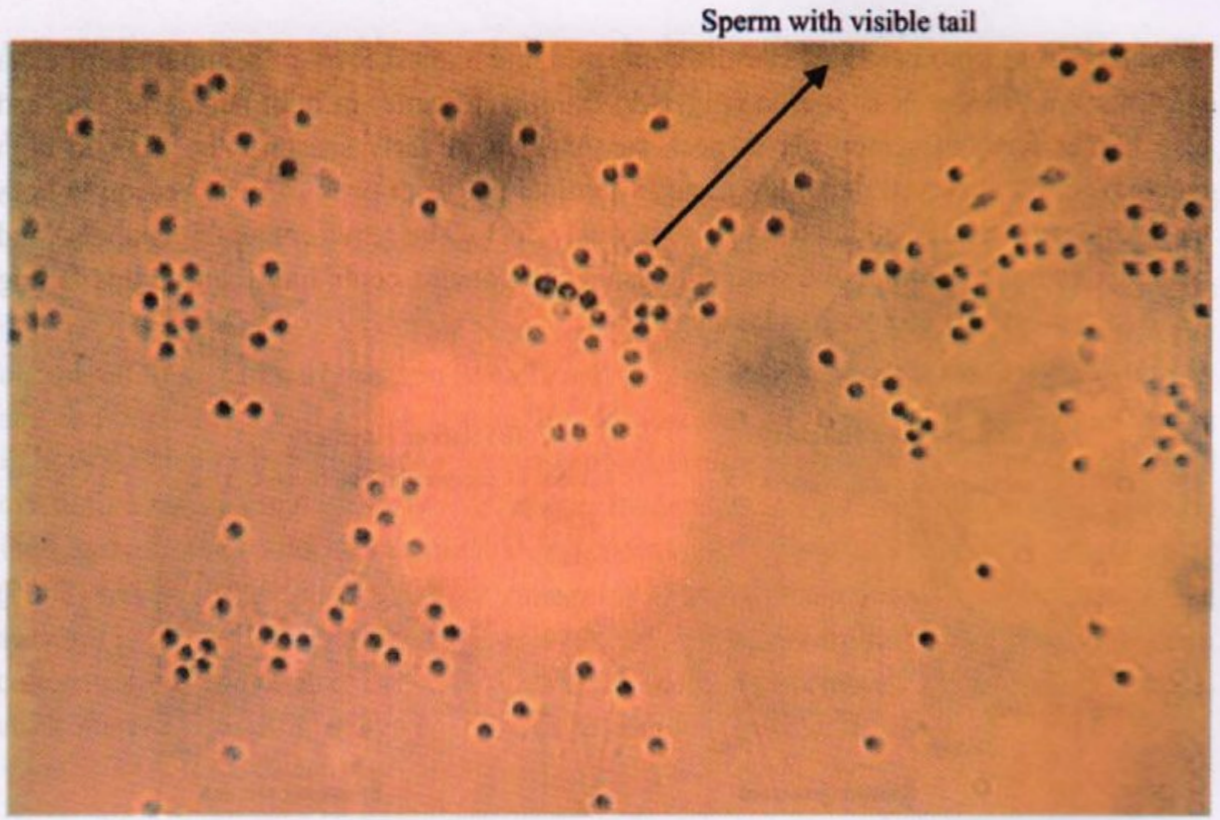

Plate 1a, Catla sperm (16x100 magnification, biomicroscope, XSZ21-5DN, China).

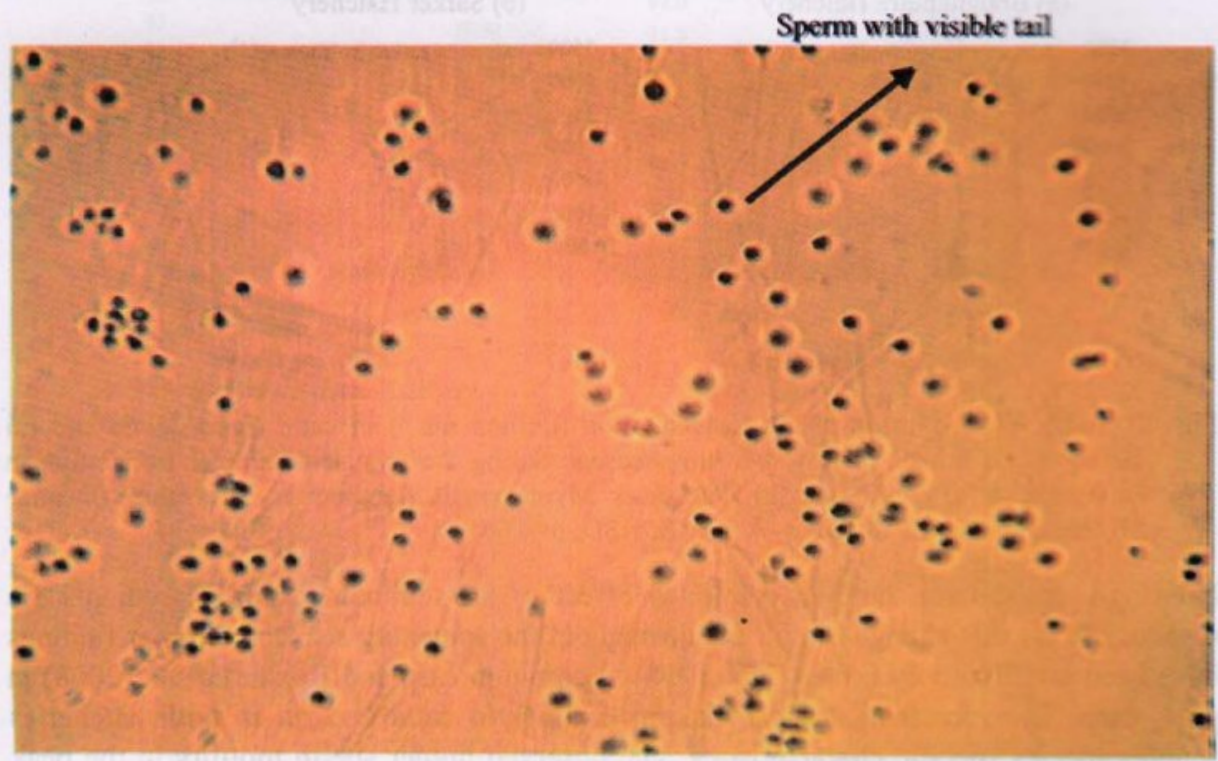

Plate Ib. Rui sperm (16x100 magnification, biomicroscope, XSE21- 5DN, China). 
3A. Catla, Catla catla

(a) Brahmaputra Hatchery

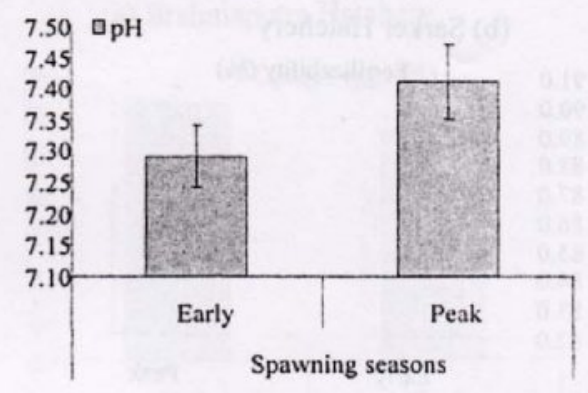

3B. Rui , Labeo rohita

(a) Brahmaputra Hatchery

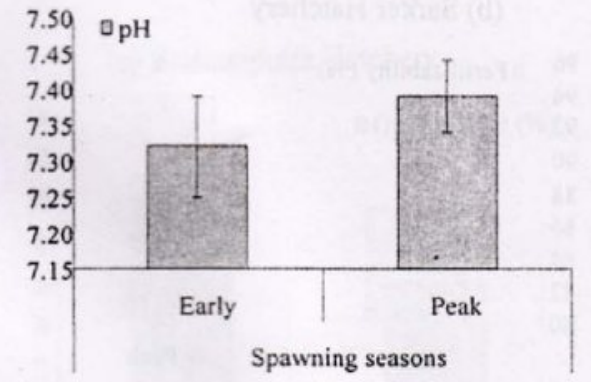

(b) Sarker Hatchery

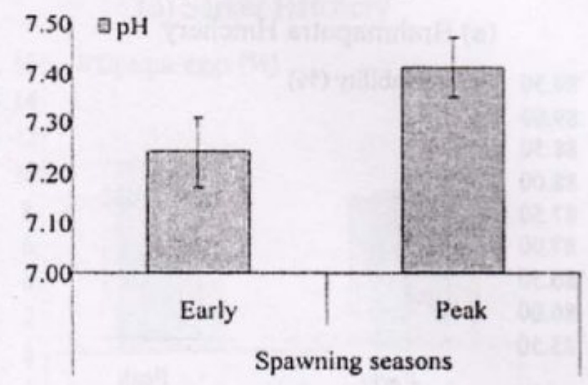

(b) Sarker Hatchery

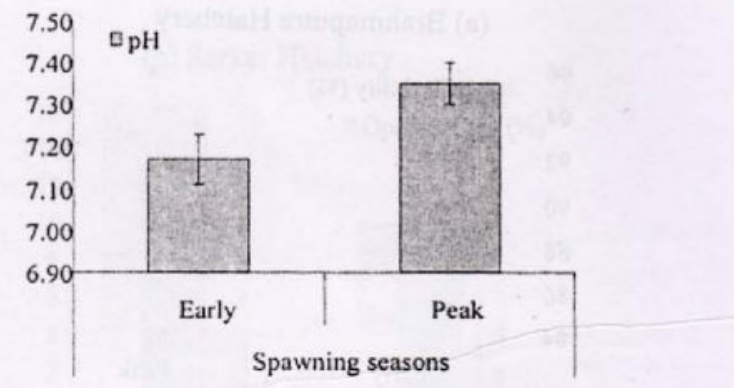

Fig. 3. (A-B) Weekly mean Seminal pH in catla Catla calla \& rui Labeo rohita found in two spawning seasons during the regular commercial operation in (a) Brahmaputra and (b) Sarker Hatcheries, Mymensingh, Bangladesh. The values (mean $\pm \mathrm{SE}$ ) are significantly different (ANOVA, HSD; $\mathrm{p}<0.05$ ).

Fertilizability (\%): Similar fertilization rate (\%) in catla was found in both seasons in both hatcheries (Fig. 4A). In contrast, significant difference in the fertilizability of rui was observed in both hatcheries. Rui had a significantly higher fertilization rate in peak season than in the early season (Fig. 4B). Variability in fertlizability for both fishes and hatcheries as observed during the spawning seasons indicates their early responsiveness in spawning. This could have resulted because of higher sperm concentration in the peak season. Lower fertilizability in the early season might be due to the absence of required environmental stimulation, cues, gonadal maturation, hormonal response etc. and the responsiveness of the fishes. Highest fertilizability in the peak season in both fishes of both hatcheries could be due to presence of favorable environmental conditions. A similar finding is confirmed by Nandi et al. 2007 in catla (91-92\%). 
4A. Catla, Catla catla

(a) Brahmaputra Hatchery

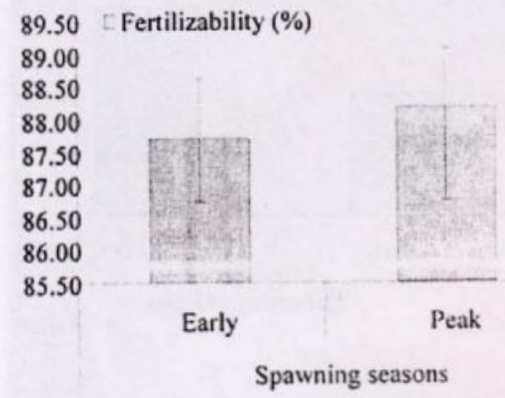

4B. Rui , Labeo rohita

(a) Brahmaputra Hatchery

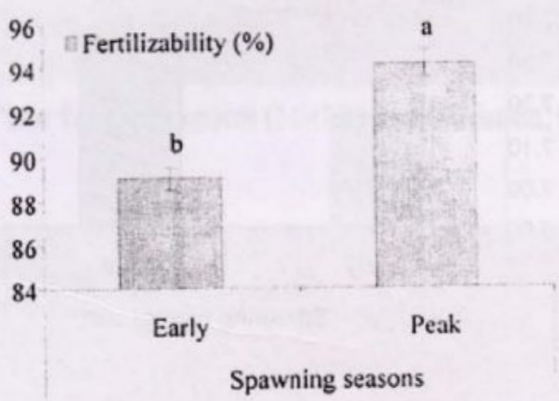

(b) Sarker Hatchery

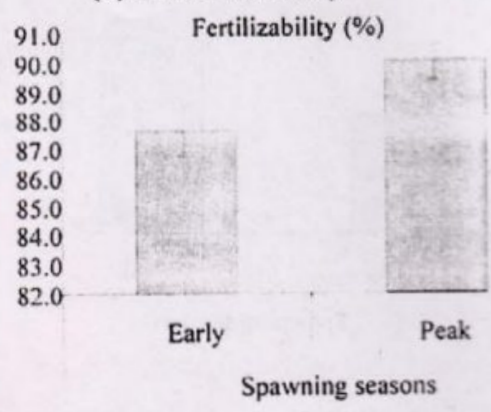

(b) Sarker Hatchery

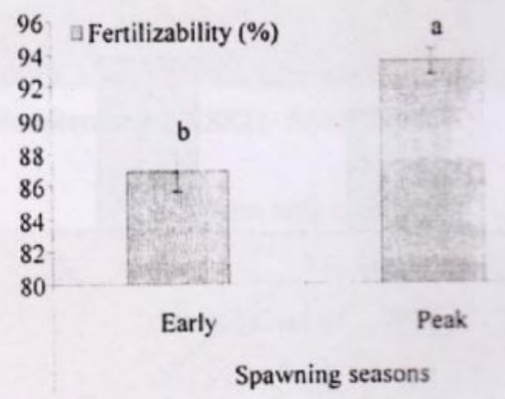

Fig. 4 (A-B). Weekly mean fertilizability rate (\%) in catla Catla catla \& rui Labeo rohita found in three spawning seasons during the regular commercial operation in Brahmaputra (a) and Sarker (b) Hatcheries, Mymensingh, Bangladesh. The values $($ mean $\pm \mathrm{SE}$ ) are significantly different (ANOVA, HSD; $<<0.05$ ).

Opaque eggs (\%): Quality of fertilized eggs in catla was found similar between the two spawning seasons (early and peak) in both hatcheries (Fig. 5A and Plate 2a). In rui, percentages of opaque eggs were found significantly lower in the peak season in both hatcheries than in the early season (Fig. 5B; Plate 2b). The observed higher level of opaque eggs in the early season than in the peak season could have resulted from the nutritional deficiency such as protein and vitamin deficiencies. However, this could also be related to the absence of optimum environmental stimulation, cues, incomplete gonadal maturation and hormonal response. 


\section{A. Catla, Catla catla}

(a) Brahmaputra Hatchery

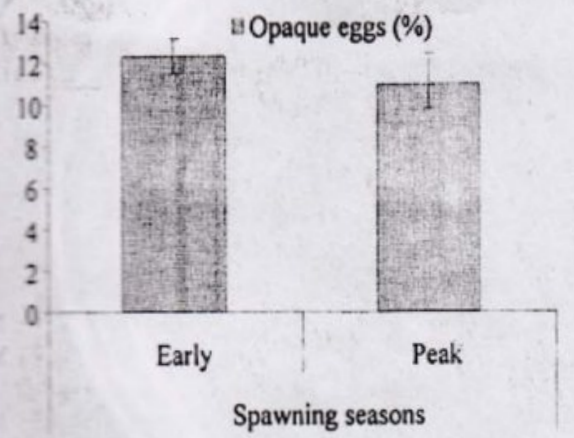

\section{B. Rui, Labeo rohita}

(a) Brahmaputra Hatchery

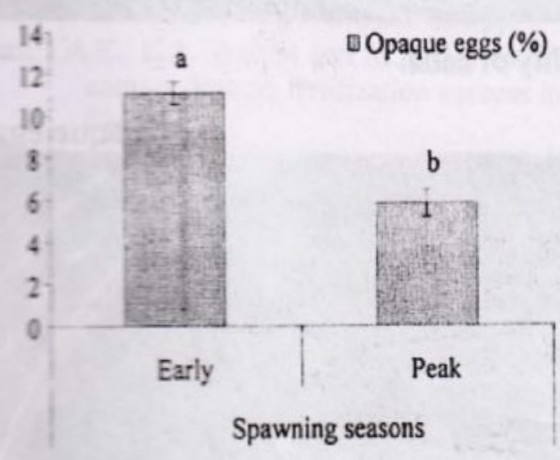

(b) Sarker Hatchery

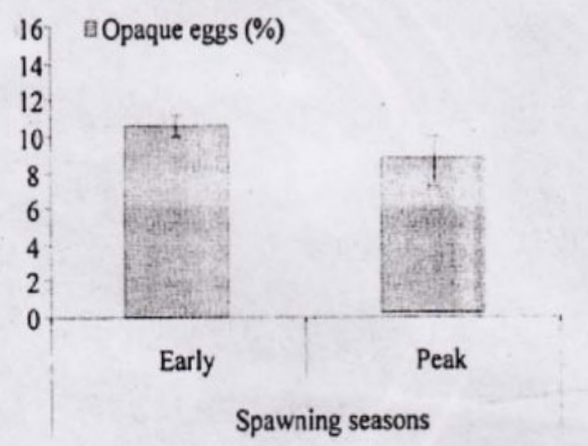

Fig. 5 (A-B). Weekly mean opaque eggs (\%) in catla Catla catla \& rui Labeo rohita found in two spawning seasons during the regular commercial operation in Brahmaputra (a) and Sarker (b) Hatcheries, Mymensingh, Bangladesh. The values (mean $\pm \mathrm{SE}$ ) are significantly different (ANOVA, HSD; $\mathrm{p}<0.05$ ). 


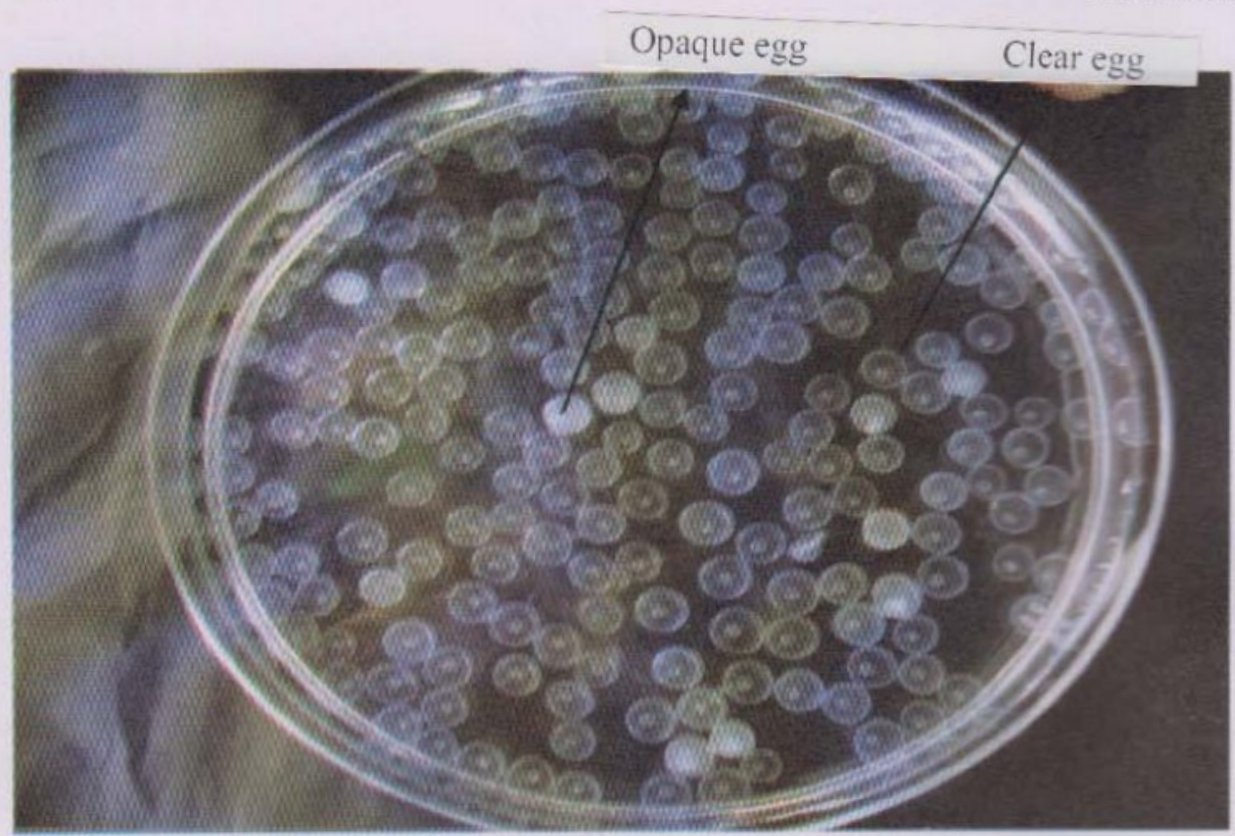

Plate 2a. Egg quality of catla.

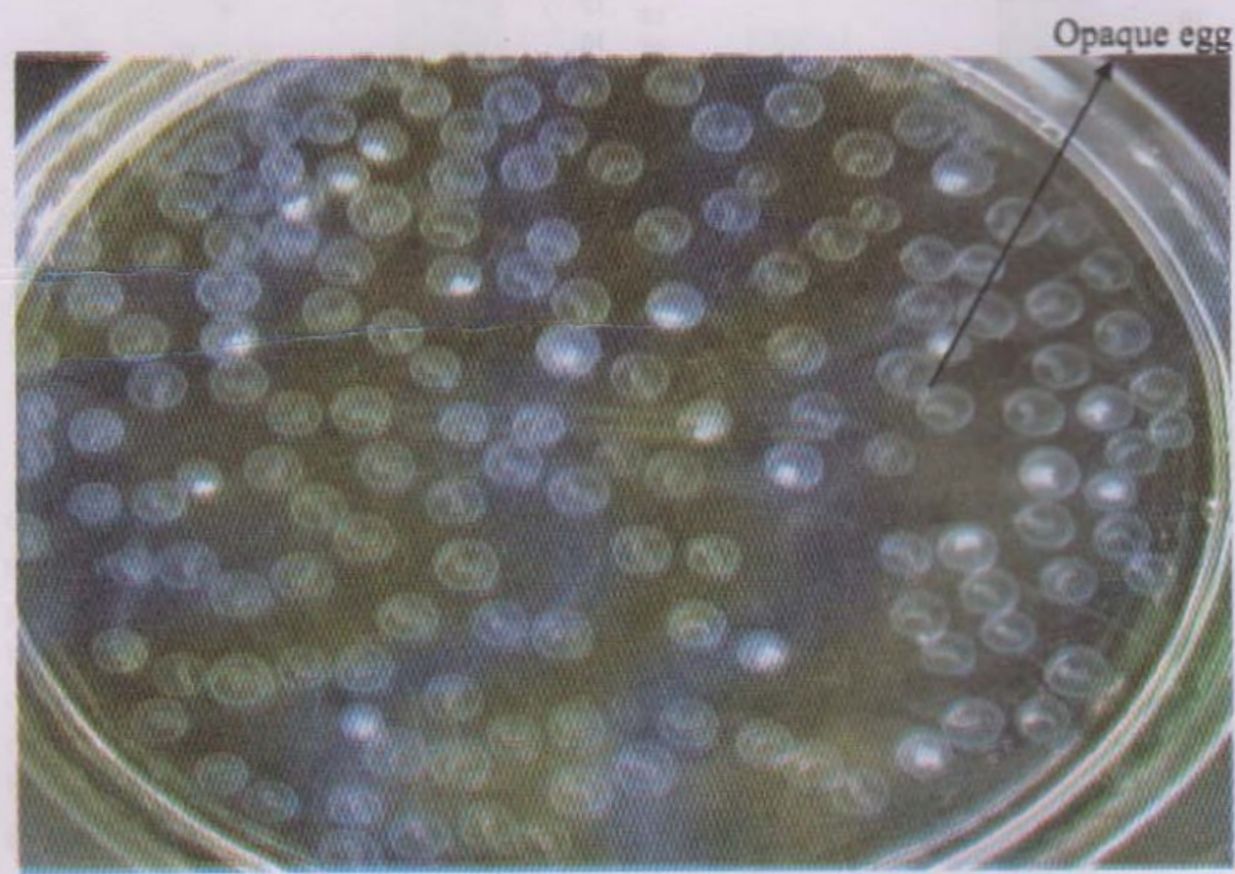

Plale 3b. Eug quality of ruh. 


\section{Acknowledgement}

We thank Ministry of Science and Technology, Govt. of the People's Republic of Bangladesh for their financial support in conducting this study.

\section{References}

Akcay, E, Y. Bozkurt, S. Secer and N. Tekin. 2004. Cryopreservation of mirror carp semen. Turkish J. Vet. Animal Sci. 28: 837-843.

Alavi, S.M.H. J. Cosson and R. Kazemi. 2006. Semen characteristics in Acipenser persicus in relation to sequential stripping. J. Appl. Ichthyol. 22: 400-405.

Alavi, S.M.H., M. Psenicka, M. Rodina, T. Policar and O. Linhart. 2008. Changes of sperm morphology, volume, density and motility and seminal plasma composition in Barbus barbus (Teleostei: Cyprinidae) during the reproductive season. Aqua. Living Res. 21: 75 80.

Billard, R. G. Cosson, G. Perchec and O. Linhart. 1995. Biology of sperm and artificial reproduction in carp. Aquaculture. 129: 95-112.

Bozkurt, Y, F. Ogretmen, U. Ercin and U. Yildiz. 2008. Seminal plasma composition and its relationship with physical spermatological parameters of grass carp (Ctenopharyngodon idella) semen: with emphasis on sperm motility. Aquacult. Res. 39: 1666-1672.

Bromage, N.R. and R.J. Roberts. 1995. Broodstock management and egg and larval quality. Blackbell Science, Oxford. 424 pp.

Butts, LA.E, E.A. Trippel and M.K. Litvak. 2009. The effect of sperm to egg ratio and gamete contact time on fertilization success in Atlantic cod Gadus morhua L. Aquaculture. 286: $89-94$.

Chondar, S.I. 1994. Induced carp breeding. CBS Publishers, $3^{\text {rd }}$ edition, India. $142 \mathrm{pp}$.

DoF (Department of Fisheries). 2012. Fisheries Statistical Yearbook of Bangladesh. Ministry of Fisheries and Livestock, Govt. of the Peoples Republic of Bangladesh, 44 pp.

Emri, M. T. Marian, L. Tron, L. Balkay and Z. Krasznai. 1998. Temperature adaptation changes in concentrations in spermatozoa and seminal plasma of common carp without affecting sperm motility. Aquaculture. 167: 85-94.

FAO. 2012. The State of World Fisheries and Aquaculture. Fisheries and Aquaculture Department, Food and Agriculture Organization of the United Nations, Rome, Italy. 38 pp.

Morisawa, M, K. Suzuki and S. Morisawa. 1983b. Effects of potassium and osmolality on spermatozoan motility of salmonid fishes. J. Exp. Biol. 107: 105-113.

Nandi, S, P. Routry, S.D. Gupta, S.C. Rath, S.D. Dasgupta, P.K. Meher and P.K. Mukhopadhyay. 2007. Reproductive performance of carp Catla catla (Ham.), reared on a formulated diet with PUFA supplementation. J. Appl.Ichthyol. 23: 684-691.

Piros, B., J. Glogowski, R. Kolman, A. Rzemieniecki, J. Domagala, A. Horvath, B. Urbanyi and A. Ciereszko. 2002. Biochemical characterization of Siberian sturgeon Acipenser baeri and starlet Acipenser ruthenus, milt plasma and spermatozoa. Fish Physiol. Biochem. 26: 289-295.

Rahman, M.M., M.S. Rahman and M. Hasan. 2011. Changes in sperm quality of silver (Hypophthalmichthys molitrix) and bighead carps (Hypophthalmichthys nobilis) during the spawning season. Asian Fish. Sci. 24(4): 413-425. 